\title{
Recovery of Treatment Doses of Surfactants from the Lungs and Vascular Compartments of Mechanically Ventilated Premature Rabbits
}

\author{
STEVEN R. SEIDNER, ALAN H. JOBE, LYNDA RUFFINI, MACHIKO IKEGAMI, AND \\ ANDREA PETTENAZZO \\ Department of Pediatrics, Harbor-UCLA Medical Center, UCLA School of Medicine, Torrance, California 90509
}

\begin{abstract}
Premature rabbits delivered by cesarean section at $28 \mathrm{~d}$ of gestation were each given intratracheally $\mathbf{7 5}$ $\mathrm{mg} / \mathrm{kg}$ of a radiolabeled preparation of either natural rabbit surfactant, natural calf surfactant, or surfactant-TA. Each newborn rabbit was ventilated for up to $6 \mathrm{~h}$ in a ventilatorplethysmograph with individual adjustments of peak inspiratory pressures to attain tidal vol of $12-15 \mathrm{~mL} / \mathrm{kg}$ body wt. Dynamic compliances were about $0.7-0.9 \mathrm{~mL} / \mathrm{cm} \mathrm{H}_{2} \mathrm{O}$. $\mathrm{kg}$ after treatment with the three surfactants and did not deteriorate during the 6-h study. Rabbits were randomly studied at $0.5,1.5,3,4.5$, and $6 \mathrm{~h}$ of age for the recovery of the labeled surfactant phosphatidylcholine in the total lungs (alveolar wash plus postlavage lung tissue). The labeled phosphatidylcholine was cleared from the total lungs of rabbits treated with natural rabbit or calf surfactants at comparable rates of about $25 \% / 6 \mathrm{~h}$. In contrast, the clearance rate of surfactant-TA phosphatidylcholine from the total lungs was not significantly different from 0 . Lipids from rabbit surfactant that had been administered intratracheally were only minimally present in the blood and liver. In other similarly treated rabbits, the lipids from radiolabeled rabbit surfactant and liposomes of dipalmitoylphosphatidylcholine that had been injected intravenously were recovered in blood and liver in substantial quantities. These studies documented significant losses of rabbit and calf surfactant phosphatidylcholine but not surfactant-TA phosphatidylcholine from the lungs of preterm ventilated rabbits. The losses were not explained by surfactant losses to the vascular compartment. (Pediatr Res 25:423-428, 1989)
\end{abstract}

\section{Abbreviations}

SP, surfactant-associated protein DPC, dipalmitoylphophatidylcholine

Surfactant replacement therapy decreases the incidence and initial severity of respiratory distress syndrome in preterm infants (1-3). However, the clearance of exogenously administered surfactants has been studied primarily in healthy spontaneously breathing fullterm or adult animals (4-8). Preterm animals with respiratory distress syndrome requiring positive-pressure ventilation may not have the same low rates of surfactant clearance

Received August 16, 1988, accepted November 20, 1988.

Correspondence and reprint requests to Steven R. Seidner, Department of Pediatrics, Harbor-UCLA Medical Center, 1000 West Carson Street, Bldg. A-17 Annex, Torrance, CA 90509.

Supported by Grant HD-12714 from the Department of Health and Human Services. and high rates of reutilization as healthy fullterm animals. Studies in adult rabbits suggest that enzymatic breakdown of phosphatidylcholine within the lung itself is the primary mechanism for surfactant phosphatidylcholine catabolism (4), and mechanical ventilation in preterm animals could change the regulation of this catabolism. In addition, preterm rabbits on positive-pressure mechanical ventilation were shown to have increased protein leaks into and out of the lungs (9) and could have increased leakage and subsequent vascular clearance of surfactant phospholipid components. Surfactant apoproteins may be lost to the vascular space and/or lymphatic compartments as preterm infants with severe respiratory distress syndrome transiently developed surfactant-antisurfactant immune complexes in the plasma following mechanical ventilation (10).

Although surfactant clearance was studied in animals given "natural" surfactants prepared from unextracted lung lavages, surfactant replacement therapy was evaluated primarily in infants given lipid extracts of animal surfactants or unextracted surfactant from human amniotic fluid (11-15). Lipid extraction resulted in the protein contents of the "modified natural" surfactants being reduced from $5-10 \%$ to $1 \%$ with essentially complete removal of contaminating serum proteins and the large mol wt surfactant-associated protein, SP-A $(16,17)$. The low mol wt lipophilic surfactant-associated proteins were still present in all three preparations. Surfactant-TA, which has also been used clinically (3), has a different lipid composition from natural surfactants as it has been enriched with DPC, palmitic acid, and tripalmitin while having cholesterol and other lipids partially removed. The sizes and structures of the lipoprotein aggregates could also affect both overall clearance of phospholipids as well as any vascular component of that clearance.

We found that we could ventilate 28 -d preterm rabbits for up to $6 \mathrm{~h}$ and asked if the clearance of "natural" surfactants would differ significantly from that found previously in spontaneously breathing 3-d-old rabbits (5-7). We compared clearance of surfactant-TA, a "modified natural" surfactant that has been used widely for surfactant replacement in clinical trials, with the clearance of natural surfactant, and we measured the appearance of surfactant lipids in other organs after both intratracheal and intravenous administration.

\section{MATERIALS AND METHODS}

Surfactant preparations. Radiolabeled $\left[{ }^{3} \mathrm{H}\right]$ choline natural rabbit surfactant was made by injecting 3-d-old rabbits intratracheally with $0.5 \mathrm{mCi}\left[{ }^{3} \mathrm{H}\right]$ choline and recovering the rabbit surfactant $20 \mathrm{~h}$ later by alveolar wash with $0.9 \%$ saline (18). The $\left[{ }^{3} \mathrm{H}\right]$ choline was synthesized from $\left[{ }^{3} \mathrm{H}\right]$ methyl iodide and unlabeled phosphatidyldimethylethanolamine by the method of Stoffel et al. (19). The large surface-active surfactant aggregates were isolated by centrifugation of the alveolar wash at $8000 \times g$ for 
$30 \mathrm{~min}$ at $4^{\circ} \mathrm{C}$ over $0.7-\mathrm{M}$ sucrose to remove cellular debris. The large aggregates recovered at the interface were then pelleted at $40000 \times g$ and resuspended in $0.9 \%$ saline for later use. Radiolabeled ${ }^{32} \mathrm{P}$ natural rabbit surfactant was made in a similar manner by injecting 3-d-old rabbits intratracheally with $0.5 \mathrm{mCi}$ ${ }^{32} \mathrm{P}$ ]orthophosphate. In this case, the large aggregates of rabbit surfactant recovered from alveolar wash 20 h later were resuspended three times in unlabeled phosphate buffer and pelleted at $40000 \times g$ to remove any remaining ${ }^{32} \mathrm{P}$-labeled free phosphate which would be cleared from the lungs differently than ${ }^{32} \mathrm{P}-$ labeled phosphatidylcholine. Unlabeled natural rabbit surfactant was obtained similarly from the pooled lung lavages of healthy adult rabbits (18). The large surfactant aggregates isolated in this manner were highly surface active in vitro and effective when used for treatment of prematurely delivered animals with respiratory failure (20). The surface pressure characteristics and adsorption time of this preparation has been described previously (21). This preparation also contained the majority of all three surfactant-associated proteins (SP-A, SP-B, and SP-C) which preferentially sediment with large aggregate fractions (22). Labeled rabbit surfactant was mixed with unlabeled rabbit surfactant to the desired sp act before tracheal instillation.

Natural calf surfactant was similarly recovered from pooled lung lavages of 1 - to 3 -d-old calf lungs. This crude calf surfactant that contains $3-4 \%$ protein by wt was radiolabeled by mixing the unlabeled natural surfactant with a suspension of liposomes made with $\left[{ }^{3} \mathrm{H}\right]$ choline labeled DPC (23). The mixture was centrifuged at $27000 \times \mathrm{g}$ for $15 \mathrm{~min}$, and the pellet was diluted with $0.45 \% \mathrm{NaCl}$ to obtain a final concentration of $25 \mathrm{mg}$ total lipid $/ \mathrm{mL}$. Liposomes associated with natural surfactant large aggregates were shown previously to have the same clearance kinetics as natural surfactant from 3-d-old rabbit lungs $(7,23)$. A free suspension of liposomes made with $\left[{ }^{3} \mathrm{H}\right]$ choline-labeled DPC was used for intravenous injection in the intravascular protocol. On electron micrographs, liposomes made in this manner were flat disks with an average diameter of $0.05 \mu \mathrm{m}$ (range, $0.03-0.09 \mu \mathrm{m})(23)$.

Surfactant-TA was prepared by Ross Laboratories following the procedure of Tanaka et al. (24) and stored frozen at $-20^{\circ} \mathrm{C}$ as a lipid suspension containing $25 \mathrm{mg}$ total lipid/mL. A comparable preparation had in vitro surface properties similar to those of natural surfactants $(21)$. This preparation contained about $1 \%$ of SP-B and SP-C on a wt-to-wt basis and no significant SP-A as described by Taeusch et al. (25). Radiolabeled surfactantTA was prepared in the same manner by the separate addition of $\left[{ }^{3} \mathrm{H}\right] 1$-palmitoyl-labeled DPC or $\left[{ }^{14} \mathrm{C}\right]$ choline-labeled DPC (New England Nuclear, Boston, MA) to the calf lung extracts during routine preparation. These labeled surfactants were then formulated into a separate water-based lipid suspension containing $25 \mathrm{mg}$ surfactant lipid $/ \mathrm{mL}$ and either $25 \mu \mathrm{Ci}\left[{ }^{3} \mathrm{H}\right] \mathrm{DPC} / \mathrm{mL}$ or $5 \mu \mathrm{Ci}\left[{ }^{14} \mathrm{C}\right] \mathrm{DPC} / \mathrm{mL}$. The labeled preparations of surfactantTA were added to the unlabeled preparation to achieve the desired specific activities.

Delivery, ventilation, and lung processing. Pregnant New Zealand White rabbit does at $28 \mathrm{~d}$ of gestation were lightly anesthetized with intravenous pentobarbital and given supplemental oxygen by face mask. Local anesthesia with $1 \%$ lidocaine was given in the abdominal wall followed by exposure of the uterus and sequential delivery of the rabbit fetuses. Each newborn was then weighed, tracheostomized with a tube made from an 18gauge needle, and injected intratracheally with $120 \mu \mathrm{L}$ of labeled rabbit surfactant, labeled calf surfactant, or labeled surfactantTA. At a concentration of $25 \mathrm{mg}$ of total lipid $/ \mathrm{mL}$, this was the equivalent of approximately $75 \mathrm{mg}$ of surfactant lipid $/ \mathrm{kg}$ body wt. The concentration and dose were chosen to approximate the preparations used in current clinical trials and to be optimal doses based on dose-response curves for exogenous surfactant in preterm rabbits (26). The randomly assigned suspension was administered after lightly compressing the chest until tracheal fluid completely filled the endotracheal tube. Several breaths of
$100 \%$ oxygen were given via an anesthesia bag immediately after the surfactant injection, and by 3 min of age, each rabbit was transferred to the temperature-controlled ventilator-plethysmograph system (9). A time-cycled pressure-limited infant ventilator was used to drive each set of 10 ventilator circuits. Each rabbit was then continuously ventilated with $100 \%$ oxygen at a rate of 40 breaths/min with an inspiratory time of $0.7 \mathrm{~s}$ and no positive end expiratory pressure. Peak inspiratory pressure was regulated individually every $20-30 \mathrm{~min}$ via a series of water columns to achieve a tidal vol of $12-15 \mathrm{~mL} / \mathrm{kg}$ body $\mathrm{wt}$, as measured with a pneumotachometer. This amount of ventilation was found to result in stable compliances and normal $\mathrm{P}_{\mathrm{CO}_{2}}$ values at the time of sacrifice. Dynamic compliance measurements were calculated by dividing tidal vol/ $\mathrm{kg}$ body wt by peak inspiratory pressure. During the course of ventilation, each rabbit was given $0.5 \mathrm{~mL}$ of $5 \%$ dextrose in water by intraperitoneal injection every $2 \mathrm{~h}$, starting at $0.5 \mathrm{~h}$ of age, to prevent the hypoglycemia that otherwise occurred. After ventilation, the rabbits were killed at 0.5 , $1.5,3,4.5$, or $6 \mathrm{~h}$, with terminal blood samples drawn from the hearts for blood gas analysis.

The lungs of each rabbit were then washed with $0.9 \% \mathrm{NaCl}$ via the endotracheal tube. Five aliquots of sufficient saline to distend the lungs $(2-3 \mathrm{~mL})$ were washed in and out of the lungs three times each and then pooled before storage at $-20^{\circ} \mathrm{C}$ for further analysis. The lungs were removed, weighed, and homogenized in $4 \mathrm{~mL}$ of water. Lipids from aliquots of the alveolar washes and lung homogenates as well as from duplicate samples of the intratracheal injection solutions were extracted with chloroform:methanol (2:1) and dried under $\mathrm{N}_{2}$ at $50^{\circ} \mathrm{C}(27)$.

Duplicate spots of phosphatidylcholine were isolated by onedimensional thin-layer chromatography on silica gel $\mathrm{H}$ plates using chloroform:methanol:acetic acid:water $(65: 25: 8: 4, \mathrm{vol} / \mathrm{vol})$ as the solvent. One of the two phosphatidylcholine spots was used for phosphorus assay, according to the method of Bartlett (28), and the other phosphatidylcholine spot was used to determine radioactivity by liquid scintillation counting with Aquasol II (New England Nuclear).

Intravascular phosphatidylcholine injection. A total of twenty rabbit fetuses at $28 \mathrm{~d}$ of gestation were sequentially delivered by cesarean section, tracheostomized, and given $75 \mathrm{mg} / \mathrm{kg}$ surfactant lipid intratracheally in the form of natural rabbit surfactant, as in the previous protocol. Fifteen of these rabbits were then injected via the external jugular vein with trace doses of ${ }^{32} \mathrm{P}$ labeled rabbit surfactant and $\left[{ }^{3} \mathrm{H}\right] \mathrm{DPC}$ liposomes, respectively, at 1 and 6 min after the onset of mechanical ventilation. The $1-$ min intravenous injection consisted of $0.1 \mathrm{mg}$ and $2 \mu \mathrm{Ci}$ of ${ }^{32} \mathrm{P}-$ labeled large aggregate rabbit surfactant suspended in normal saline; the 6-min injection consisted of $0.1 \mathrm{mg}$ and $10 \mu \mathrm{Ci}$ of the free suspension of $\left[{ }^{3} \mathrm{H}\right] \mathrm{DPC}$ liposomes in normal saline. The injections were given separately to prevent the association of the liposomes with the large aggregate rabbit surfactant (23). These rabbits were randomly assigned to receive either $10 \mathrm{~min}, 1 \mathrm{~h}$, or 6 h of mechanical ventilation in the manner previously described. The remaining five rabbits served as controls and were not injected intravenously. In these rabbits, the intratracheal rabbit surfactant was labeled with $0.5 \mu \mathrm{Ci}$ of ${ }^{32} \mathrm{P}$-labeled rabbit surfactant, and they were mechanically ventilated for $6 \mathrm{~h}$.

When the animals were killed, $0.5-1.0 \mathrm{~mL}$ of blood was drawn from the heart of each rabbit for a terminal blood gas and for a measurement of radioactivity. The lungs and livers of all the rabbits were removed, weighed, and homogenized in $4 \mathrm{~mL}$ of water. After organ removal, the fetal carcasses were homogenized in $100 \mathrm{~mL}$ of water, and aliquots were taken for recovery of radioactivity. Aliquots of liver, carcasses, lung, and hemolyzed blood as well as duplicate samples of the intratracheal and intravenous injection solutions were extracted with chloroform:methanol $(2: 1)$ and dried under $\mathrm{N}_{2}$ at $50^{\circ} \mathrm{C}$ in scintillation vials to determine total lipid radioactivity by liquid scintillation counting. Total recovery of radioactivity in blood was calculated assuming a blood vol of $100 \mathrm{~mL} / \mathrm{kg}$. 
Data analysis. Rabbits were excluded from analysis for terminal $\mathrm{pH}$ values $<7.10$ and/or $\mathrm{p}_{\mathrm{CO}_{2}}$ values $>60 \mathrm{~mm} \mathrm{Hg}$. Results are reported as group means \pm SEM unless otherwise indicated. The rates of clearance of the different surfactants were calculated from the slopes of the linear regression curves of the recovery percentages. The amount present in the lung at 0 time was calculated for each group of rabbits from the $y$-intercept value of the linear regression line for the recovery of radiolabeled phosphatidylcholine in the total lung (alveolar wash + lung homogenate) versus time. The 0 intercept values thus calculated were $85-95 \%$ of the quantities injected, as estimated by measurements of the injection solutions. Differences between groups were tested by ANOVA followed by the Student Newman-Keuls multiple comparison procedure.

\section{RESULTS}

Description of animals. Of the preterm rabbits, $60 \%$ satisfied the $\mathrm{pH}$ and $\mathrm{P}_{\mathrm{CO}_{2}}$ exclusion criteria and were included in the results. The numbers of rabbits analyzed at the various times for each of the three intratracheal surfactant treatments are shown in Table 1 . In addition, the mean body wt and the mean tidal vol are given. There were no major differences in the clinical variables of peak inspiratory pressure, $\mathrm{P}_{\mathrm{CO}_{2}}, \mathrm{pH}$, or dynamic compliance either between surfactant preparations or over time (Fig. 1).

Lung clearance of surfactant phosphatidylcholine. Recovery curves for labeled rabbit surfactant phosphatidylcholine were linearly regressed for the alveolar washes and total lungs (alveolar wash + lung homogenate) (Fig. $2 A$ ). By 6 h, there was $25 \%$ loss of the labeled phosphatidylcholine from the total lung. The clearance from the airway-alveolar pool was initially very rapid, with $30 \%$ of the intratracheally administered treatment dose being lung associated by $0.5 \mathrm{~h}$. After this initial rapid redistribution, there was an airway-alveolar clearance of $6.5 \%$ of the remaining phosphatidylcholine/ $\mathrm{h}$ as estimated by linear regression. By 3-4 h on the regression line $50 \%$ of the labeled phosphatidylcholine that was recovered had become lung associated. The total airway-alveolar phosphatidylcholine pools as measured by phosphorus analysis had similar clearances (data not shown).

The linearly regressed clearance curves for natural calf surfactant phosphatidylcholine were virtually identical to those of the natural rabbit surfactant (Fig. $2 B$ ). The clearances at $6 \mathrm{~h}$ estimated from the regression lines were $27 \%$ from the total lungs and $61 \%$ from the airway-alveolar pool. The calf surfactant was also $50 \%$ lung associated by $3-4 \mathrm{~h}$.

Table 1. Study animals

\begin{tabular}{ccccc}
\hline & $\begin{array}{c}\text { Time } \\
\text { animals } \\
\text { were killed } \\
(\mathrm{h})\end{array}$ & $n$ & $\begin{array}{c}\text { Mean body wt } \\
(\mathrm{g})\end{array}$ & $\begin{array}{c}\text { Mean tidal vol } \\
(\mathrm{mL} / \mathrm{kg})\end{array}$ \\
\hline Rabbit surfactant & 0.5 & 7 & $35 \pm 1$ & $12.4 \pm 0.3$ \\
& 1.5 & 8 & $36 \pm 2$ & $13.2 \pm 0.6$ \\
& 3.0 & 6 & $32 \pm 2$ & $11.8 \pm 0.4$ \\
Calf surfactant & 4.5 & 6 & $34 \pm 1$ & $11.7 \pm 0.5$ \\
& 6.0 & 7 & $33 \pm 2$ & $12.9 \pm 0.3$ \\
& 0.5 & 7 & $29 \pm 2$ & $15.0 \pm 0.9$ \\
Surfactant-TA & 1.5 & 7 & $33 \pm 3$ & $15.0 \pm 0.6$ \\
& 3.0 & 5 & $32 \pm 2$ & $13.8 \pm 0.4$ \\
& 4.5 & 6 & $31 \pm 3$ & $13.8 \pm 0.4$ \\
& 6.0 & 7 & $37 \pm 3$ & $13.3 \pm 0.2$ \\
& 0.5 & 6 & $37 \pm 2$ & $13.7 \pm 0.7$ \\
& 1.5 & 8 & $34 \pm 2$ & $12.8 \pm 0.5$ \\
& 3.0 & 7 & $36 \pm 2$ & $12.6 \pm 0.5$ \\
& 4.5 & 8 & $36 \pm 3$ & $11.9 \pm 0.3$ \\
& 6.0 & 9 & $39 \pm 1$ & $12.6 \pm 0.2$ \\
\hline
\end{tabular}
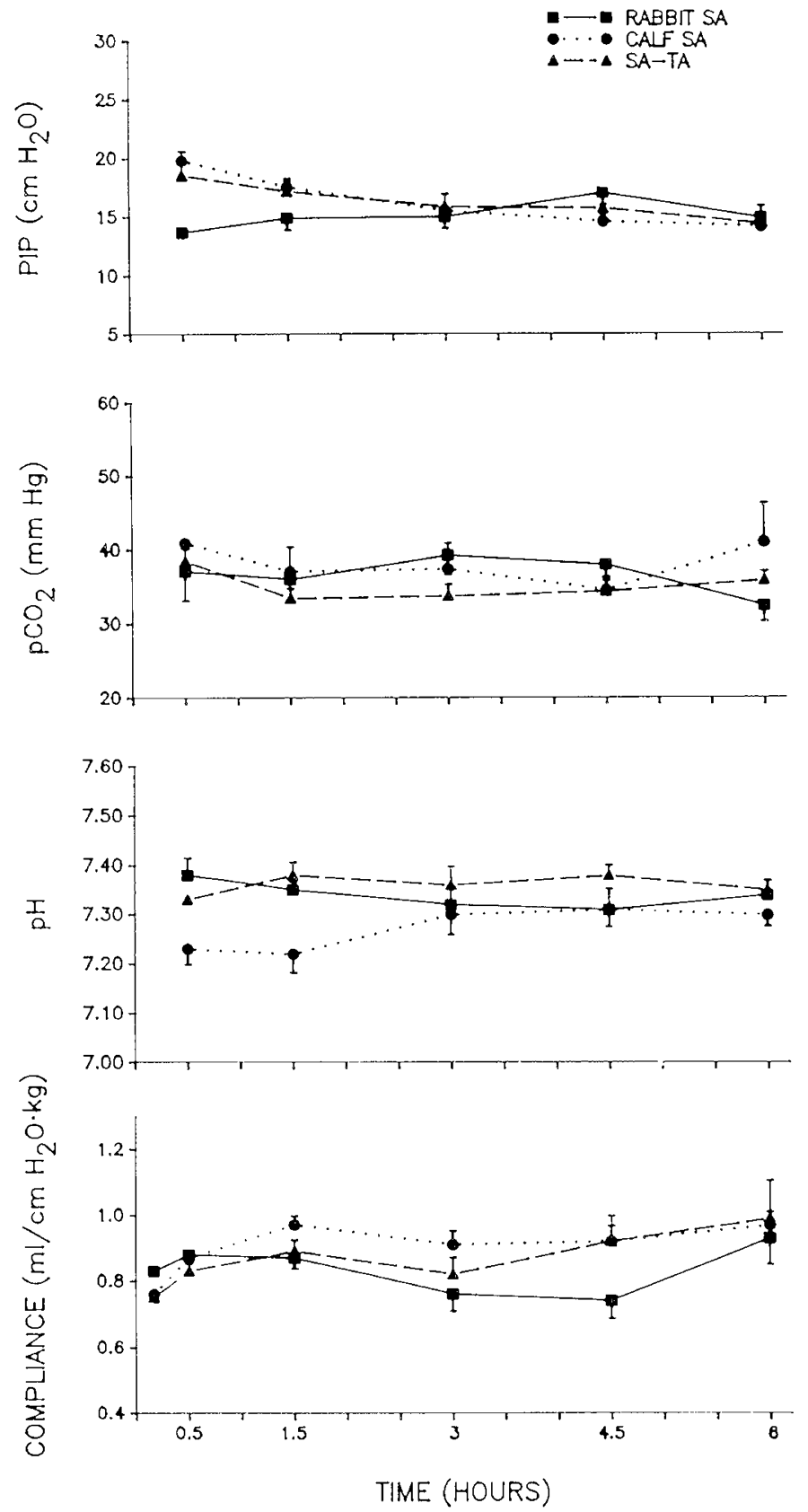

Fig. 1. Peak inspiratory pressure (PIP), $\mathrm{P}_{\mathrm{CO}_{2}}, \mathrm{pH}$, and dynamic compliance values for rabbits receiving treatment doses of the three different surfactants. The points in all graphs here and in Figure 2 represent the group mean values and SEM. There were no significant differences between the compliances of the rabbits receiving the three different surfactant preparations, and there was no deterioration in compliance values with increased time of ventilation.

Surprisingly, the clearance curves for choline-labeled phosphatidylcholine in surfactant-TA were quite different from those for the other surfactants (Fig. 2C). There was essentially no clearance from the total lung over the 6-h experiment, and the clearance at $6 \mathrm{~h}$ from the airway-alveolar pool was only $45 \%$. When the phosphatidylcholine was labeled in the 1-palmitoyl residue, the results were essentially the same as when it was labeled in the choline moiety, as shown by the constant ratio in the recovered counts over the 6-h experiment (Fig. 2D).

Vascular and organ recovery of intravenous and intratracheal lipids. Lipids from ${ }^{32} \mathrm{P}$-labeled large aggregate rabbit surfactant 

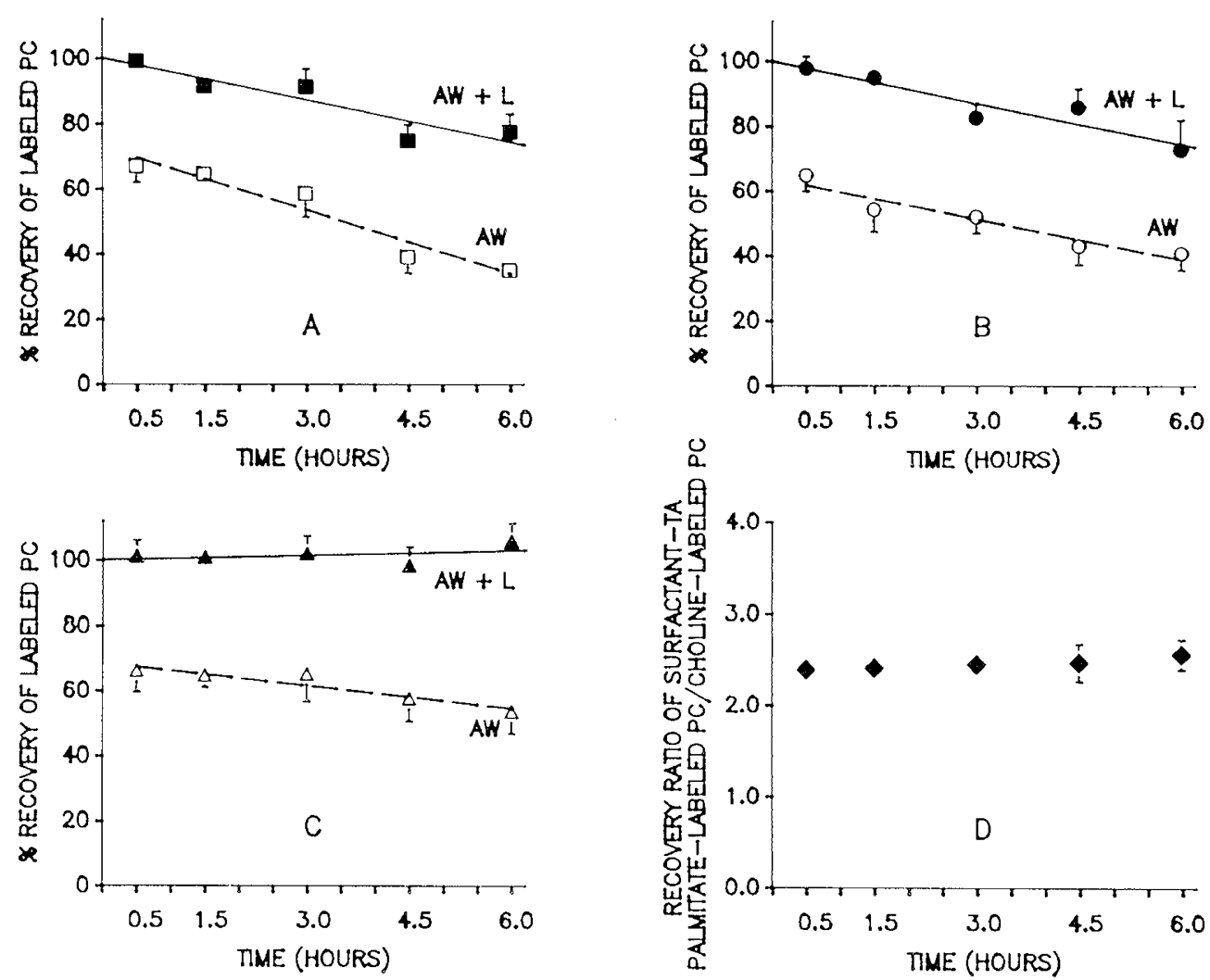

Fig. 2. The 6-h recovery curves for $\left[{ }^{3} \mathrm{H}\right]$ choline-labeled rabbit surfactant, $A ;\left[{ }^{3} \mathrm{H}\right]$ choline-labeled calf surfactant, $B$; and $\left[{ }^{14} \mathrm{C}\right]$ choline-labeled surfactant-TA, C. Results are shown for both alveolar wash (AW) and total lung (AW $+\mathrm{L}$ ) for rabbits killed at the indicated times. The group mean values are regressed and normalized to $100 \%$ recovery in the total lung at 0 time. $D$, the group mean ratios are shown for the normalized regressed recoveries of $\left[{ }^{3} \mathrm{H}\right]$ palmitoyl-labeled surfactant-TA compared to those for $\left[{ }^{14} \mathrm{C}\right]$ choline-labeled surfactant-TA.

Table 2. Percentage of recovery of labeled lipid given intravenously as ${ }^{32} \mathrm{P}$ rabbit surfactant and liposomes of [ $\left.{ }^{3} H\right] D P C^{*}$ and percentage of recovery of ${ }^{32} \mathrm{P}$ rabbit surfactant lipid lost from lungs in $6 \mathrm{~h}$ after intratracheal administration

\begin{tabular}{|c|c|c|c|c|c|}
\hline \multirow[b]{2}{*}{ me animal was killed } & \multicolumn{5}{|c|}{$\%$ recovery (group mean $\pm \mathrm{SD}$ ) } \\
\hline & Livert & Lungs $\dagger$ & Blood & Carcass: & Total \\
\hline \multirow{2}{*}{\multicolumn{6}{|c|}{$\begin{array}{l}{ }^{32} \mathrm{P} \text { r: } \\
{ }^{2} \text { bit surfactant and } \\
\text { venously } \\
10 \mathrm{~min}\end{array}$}} \\
\hline & & & & & \\
\hline \multirow[t]{2}{*}{${ }^{32} \mathrm{P}$} & 73.6 & 3.5 & 12.5 & 19.7 & 100 \\
\hline & \pm 16.8 & \pm 1.1 & \pm 3.7 & \pm 7.4 & \pm 12 \\
\hline \multirow{2}{*}{${ }^{3} \mathrm{H}$} & $\begin{array}{r}50.4 \\
+148\end{array}$ & $\begin{array}{r}5.3 \\
+0.4\end{array}$ & $\begin{array}{r}37.9 \\
+8.4\end{array}$ & 36.7 & 100 \\
\hline & \multicolumn{5}{|c|}{$1 \mathrm{hr}$} \\
\hline \multirow[t]{2}{*}{${ }^{32} \mathrm{P}$} & 69.3 & 2.7 & 11.0 & 20.8 & 94.6 \\
\hline & \pm 5.8 & \pm 1.3 & \pm 4.0 & \pm 10.1 & \pm 14.4 \\
\hline \multirow[t]{2}{*}{${ }^{3} \mathrm{H}$} & 30.9 & 5.1 & 37.5 & 43.9 & 86.1 \\
\hline & \pm 1.8 & \pm 0.8 & \pm 5.7 & \pm 2.5 & \pm 2.2 \\
\hline \multicolumn{6}{|l|}{$6 \mathrm{hr}$} \\
\hline \multirow[t]{2}{*}{${ }^{32} \mathrm{P}$} & 46.7 & 1.8 & 4.3 & 11.5 & 61.4 \\
\hline & \pm 28.5 & \pm 0.3 & \pm 1.4 & \pm 5.8 & \pm 23.4 \\
\hline \multirow[t]{2}{*}{${ }^{3} \mathrm{H}$} & 32.2 & 5.1 & 11.9 & 35.7 & 76.0 \\
\hline & \pm 8.8 & \pm 0.8 & \pm 0.8 & \pm 4.1 & \pm 3.9 \\
\hline \multicolumn{6}{|l|}{$\begin{array}{l}{ }^{32} \mathrm{P} \text { rabbit surfactant given in- } \\
\text { tratracheally }\end{array}$} \\
\hline \multirow[t]{2}{*}{$6 \mathrm{hr}$} & $\begin{array}{r}0.71 \\
+027\end{array}$ & & 0.12 & 5.4 & 6.1 \\
\hline & \pm 0.27 & & \pm 0.04 & \pm 2.7 & \pm 3.3 \\
\hline
\end{tabular}

* Recoveries were normalized to a total recovery of $100 \%$ at $10 \mathrm{~min}$.

t The percentage of recoveries of radiolabel reported for lungs, liver, and carcass included the blood content of those organs sampled.

The carcass recoveries were performed after removal of a blood sample, liver, and lungs. 
that was injected intratracheally were cleared from the lungs similarly to the $25 \%$ clearance over $6 \mathrm{~h}$ found for the $\left[{ }^{3} \mathrm{H}\right]$ choline-labeled rabbit surfactant phosphatidylcholine, but lipids were only minimally present in the blood and liver (Table 2). However, lipids from the same preparation of ${ }^{32} \mathrm{P}$-labeled rabbit surfactant injected intravenously were still present in the blood and liver in substantial quantities at $6 \mathrm{~h}$. In both cases, there were significant quantities of labeled lipid recovered in the carcasses after removal of the lungs and liver that could not be explained by the label recovered from the blood. The lipids from sonicated liposomes of ${ }^{3} \mathrm{H}$-labeled DPC that were injected intravenously were also recovered in substantial quantities at $6 \mathrm{~h}$, but to a greater degree in the blood and carcasses and to a lesser degree in the liver than the ${ }^{32} \mathrm{P}$-labeled large aggregate rabbit surfactant lipids.

\section{DISCUSSION}

The clearance of exogenous surfactant had not been studied previously in preterm animals requiring mechanical ventilation. Rabbits that were $3 \mathrm{~d}$ old were used previously as a model of the developing animal. However, these rabbits were healthy, spontaneously breathing, and had large endogenous surfactant pools of about $80 \mathrm{mg}$ phospholipid/kg body wt (29). Rabbits that were $3 \mathrm{~d}$ old cleared surfactant phospholipids very slowly and were able to recycle or reprocess them efficiently in the lung (30). The recycling pathway for phosphatidylcholine was estimated to be about $95 \%$ efficient; de novo synthesis accounted for only $5 \%$ of the phosphatidylcholine secreted into the alveolar pool (30). The $28-\mathrm{d}$ gestation rabbits used in this study required mechanical ventilation and would be expected to have endogenous surfactant pools of about $2-3 \mathrm{mg}$ phospholipid/ $\mathrm{kg}$ body wt (31). After receiving treatment doses of $75 \mathrm{mg} / \mathrm{kg}$ natural rabbit surfactant or calf surfactant, the rabbits cleared about $25 \%$ of the labeled phosphatidylcholine from their lungs over the 6-h study period. If they had maintained this clearance rate, they would have cleared the total treatment dose from their lungs by $24 \mathrm{~h}$. This would be much more rapid than the phosphatidylcholine clearance rates of $10-15 \% / 24 \mathrm{~h}$ reported for 3 -d-old rabbits after administration of either tracer or treatment doses of natural rabbit or calf surfactant (6). In fact, the preterm rabbits in this study cleared natural surfactant phosphatidylcholine from the lungs at a rate of $4 \% / \mathrm{h}$, a value similar to the clearance rates of $3-4 \% / h$ reported previously in healthy, adult rabbits (4).

The different species source of the surfactant did not alter the lung clearance of phosphatidylcholine. However, treatment doses of surfactant-TA were not cleared at a detectable rate from the mechanically ventilated preterm lungs, whereas treatment doses of surfactant-TA were cleared from 3-d-old rabbit lungs in a way similar to clearance of natural rabbit and calf surfactants (7). In addition, the rate of lung uptake of the intratracheally-administered surfactant-TA phosphatidylcholine from the airspaces of these preterm rabbits (as estimated by the alveolar wash procedure) was also slower than that seen with the natural surfactants, whereas in 3-d-old rabbits the rate of lung uptake of phosphatidylcholine from intratracheally-administered surfactant-TA was similar to that seen with intratracheal calf surfactant (7). In vitro studies would suggest that the decreased lung uptake and perhaps clearance of the lipid-solvent-extracted surfactant in the preterm rabbits might be related to the loss of SP-A during the extraction procedure (32). However, although it is tempting to speculate that these differences in lung uptake and clearance of surfactantTA were not seen in 3-d-old rabbits because of larger endogenous pools of SP-A, further studies investigating the dose-response of preterm ventilated animals to exogenous SP-A are needed.

The utility of the 28-d gestation preterm rabbit model to study surfactant metabolism was somewhat limited by our inability to maintain mechanical ventilation successfully for longer than 6 h. However, subsequent studies in our laboratory using mechanically ventilated preterm lambs given treatment doses of natural sheep surfactant or surfactant-TA documented $30 \%$ clearance of natural sheep surfactant over $24 \mathrm{~h}$ compared to $10 \%$ clearance of surfactant-TA (33). Although these differences were not significant, they were consistent with a somewhat more rapid clearance of natural surfactant phosphatidylcholine from preterm ventilated lungs as well as qualitatively different clearance rates for natural surfactant and surfactant-TA phosphatidylcholine.

Dynamic compliance responses after intratracheal administration were independent of the surfactant preparation and did not deteriorate during the $6-\mathrm{h}$ ventilation. We showed previously that ventilated $27-d$ preterm rabbits had incremental improvements in dynamic compliance with increasing doses of intratracheal rabbit surfactant up to $50 \mathrm{mg} / \mathrm{kg}$ with no further improvement at a dose of $75 \mathrm{mg} / \mathrm{kg}$ (26). Therefore, even after seeing a $25 \%$ loss of the $75 \mathrm{mg} / \mathrm{kg}$ natural surfactant dose over $6 \mathrm{~h}$, we did not expect to see a change in the dynamic compliances unless surfactant inactivation occurred. The rabbits treated with intratracheal surfactant-TA showed no appreciable clinical deterioration associated with their minimal clearance of the treatment doses and had no increase in mortality compared to the other treatment groups. We did not expect the decreased clearance of surfactant-TA to be detrimental as the adaptation of the term newborn is to recycle surfactant phospholipids rather than clear them (30).

The reason for the increased clearance of natural surfactants seen in the preterm rabbits could be related to mechanical ventilation and/or lung immaturity. Lung structure, enzyme levels within the subcellular components of the lung, vascular endothelial and airspace epithelial permeabilities, endogenous surfactant phospholipids and associated proteins, as well as hormonal effects are all gestationally dependent $(31,34,35)$. Increased protein leaks into and out of the lungs of preterm ventilated rabbits were found in our laboratory with both increased ventilatory pressure requirements (9) and with decreased gestational age (35). Therefore, increased clearance of phosphatidylcholine from preterm ventilated rabbit lungs could result from an epithelial leak of phospholipids followed by vascular clearance. Although this possibility is supported by the development of surfactant-antisurfactant immune complexes in the plasma of preterm infants with severe respiratory distress syndrome (10), we found no significant vascular clearance of surfactant lipids in our surfactant-treated preterm ventilated rabbits. The recovery of radiolabeled lipids in the liver and blood of those rabbits given treatment doses of rabbit surfactant intratracheally and mechanically ventilated for $6 \mathrm{~h}$ was less than $1 \%$ of the label cleared from the lung. In contrast, we had $51 \%$ recovery at $6 \mathrm{~h}$ in the liver and blood in rabbits given labeled large aggregate rabbit surfactant intravenously. A suspension of radiolabeled liposomes of DPC, consisting of smaller aggregates than the natural surfactant, was given intravenously and maintained a higher concentration in the blood while appearing to a lesser degree in the liver, but $44 \%$ of the labeled lipids were still recovered in these two fractions at $6 \mathrm{~h}$. The persistence of lipids from various sized aggregates in the vascular compartments over 6 h suggested that the inability to recover lipids lost from the lungs after intratracheal treatment was due to catabolic activity in the lung itself. It remains a possibility that less mature animals with more severe lung disease requiring exceptionally high ventilatory pressures and not given surfactant replacement might have more permeable lungs that could leak endogenous surfactant phospholipids to the vascular compartment.

The reason for the decreased clearance of surfactant-TA from the mechanically ventilated preterm rabbit lungs was unclear. There were no significant differences in the ventilatory pressures used for the animals treated with the different surfactants. In addition to the possible effects resulting from the loss of SP-A during the extraction procedure, the different nature and sizes of the surfactant-TA aggregates might alter the intracellular processing and catabolism in the lungs. The enrichment of surfactant- 
TA with DPC, tripalmitin, and palmitic acid, and the selective partial removal of cholesterol might also change the nature of lung uptake and intracellular processing. We were reassured that this modified natural surfactant used clinically for the treatment of infants with respiratory distress syndrome was certainly not cleared more rapidly than the natural surfactants.

In summary, treatment doses of natural rabbit and calf surfactant phospholipids were cleared similarly and relatively rapidly from the lungs of mechanically ventilated preterm rabbits. Vascular clearance of phosphatidylcholine did not appear to be a significant contributing factor in these animals. Surfactant-TA phosphatidylcholine showed no appreciable loss over $6 \mathrm{~h}$ of ventilation. Dynamic compliance responses were independent of the surfactant preparation and did not deteriorate during the 6$h$ ventilatory course.

\section{REFERENCES}

1. Enhorning G, Shennan A, Possmayer F, Dunn M, Chen CP, Milligan J 1985 Prevention of neonatal respiratory distress syndrome by tracheal instillation of surfactant: a randomized clinical trial. Pediatrics 76:145-153

2. Kwong MS, Egan EA, Notter RH, Shapiro DL 1985 Double-blind clinical trial of calf lung surfactant extract for the prevention of hyaline membrane diseasc in extremely premature infants. Pediatrics 76:585-592

3. Fujiwara T, Chida S, Watabe Y, Maeta H, Morita T, Abe T 1980 Artificial surfactant therapy in hyaline-membrane disease. Lancet I:55-59

4. Pettenazzo A, Ikegami M, Seidner S, Jobe A 1988 Clearance of surfactant phosphatidylcholine from adult rabbit lungs. J Appl Physiol 64:120-127

5. Oguchi K, Ikegami M, Jacobs H, Jobe A 1985 Clearance of large amounts of natural surfactant and DPPC from lungs of 3-day-old rabbits following tracheal injection. Exp Lung Res 9:22 I-235

6. Pettenazzo A Oguchi K, Seidner S, Ikegami M, Berry D, Jobe A 1986 Clearance of natural surfactant phosphatidylcholine from 3-day-old rabbit lungs: effects of dose and species. Pediatr Res 20:1139-1142

7. Pettenazzo A, Jobe A, Ikegami M, Seidner S 1988 Clearance of treatment doses of surfactant: effect of lipid extraction and aggregate sizes. Biol Neonate $53: 23-31$

8. Jacobs H, Jobe A, Ikegami M, Jones S 1982 Surfactant phosphatidylcholine source, fluxes, and turnover times in 3-day-old, 10-day-old, and adult rabbits. J Biol Chem 257:1805-1810

9. Ikegami M, Berry D, Elkady T, Pettenazzo A Seidner S, Jobe A 1987 Corticosteroids and surfactant change lung function and protein leaks in the Iungs of ventilated premature rabbits. J Clin Invest 79:1371-1378

10. Strayer DS, Merritt TA, Iwebuga-Mukasa J, Hallman M 1986 Surfactant-antisurfactant immune complexes in infants with respiratory distress syndrome. Am J Pathol 122:353-362

11. Shapiro DL, Notter RH, Morin FC, Deluga KS, Golub LM, Sinkin RA, Weiss KI, Cox C 1985 Double-blind, randomized trial of a calf lung surfactant extract administered at birth to very premature infants for prevention of respiratory distress syndrome. Pediatrics 76:593-599

12. Gitlin JD, Soll RF, Parad RB, Horbar JD, Feldman HA, Lucey JF, Taeusch HW 1987 Randomized controlled trial of exogenous surfactant for the treatment of hyaline membrane disease. Pediatrics 79:31-37

13. Raju TNK, Vidyasagar D, Bhat R, Sobel D, McCulloch KM, Anderson M, Maeta H, Levy PS, Furner S 1987 Double-blind controlled trial of singledose treatment with bovine surfactant in severe hyaline membrane disease. Lancet 1:651-655

14. Merritt TA, Hallman M, Bloom BT, Berry C, Benirschke K, Sahn D, Key T,
Edwards D, Jarvenpaa A, Pohjavuori M, Kankaanpaa K, Kunnas M, Paatero H, Rapola J, Jaaskelainen J 1986 Prophylactic treatment of very premature infants with human surfactant. N Engl J Med 315:785-790

15. Hallman M, Merritt TA, Jarvenpaa A-L, Boynton B, Mannino F, Gluck L Moore T, Edwards D 1985 Exogenous human surfactant for treatment of severe respiratory distress syndrome: a randomized prospective clinical trial. J Pediatr 106:963-969

16. Fujiwara $T 1984$ Surfactant replacement in neonatal RDS. In: Robertson B, Van Golde LMG, Batenburg JJ (eds) Pulmonary Surfactant. Elsevier Science Publishers, Amsterdam, pp 479-503

17. Possmayer $F 1988$ A proposed nomenclature for pulmonary surfactant-associated proteins. Am Rev Resp Dis 138:990-998

18. Jobe A, Ikegami M, Glatz T, Yoshida Y, Diakomanolis E, Padbury J 1981 Duration and characteristics of treatment of premature lambs with natural surfactant. J Clin Invest 67:370-375

19. Stoffel W, LeKim D, Tschung TS 1971 A simple chemical method for labeling phosphatidylcholine and sphingomyelin in the choline moiety. Z Physiol Chem 352:1058-1064

20. Jobe A, Ikegami M 1984 The prematurely delivered lamb as a model for studies of neonatal adaptation. In: Nathanielsz PW (ed) Animal models in fetal medicine. Perinatology Press, Ithaca, NY, pp 1-30

21. Ikegami M, Agata Y, Elkady T, Hallman M, Berry D, Jobe A 1987 A comparison of four surfactants: in vitro surface properties and responses of preterm lambs to treatment at birth. Pediatrics 79:38-46

22. Wright JR, Benson BJ, Williams MC Goerke J, Clements JA 1984 Protein composition of rabbit alveolar surfactant subfractions. Biochim Biophys Acta 791:320-332

23. Ikegami M, Jobe A, Duane G 1985 Liposomes of dipalmitoylphosphatidycholine associate with natural surfactant. Biochim Biophys Acta 835:352-359

24. Tanaka Y Takei T, Kanazawa Y 1983 Lung surfactants: II. effects of fatty acids, triacylglycerols, and protein on the activity of lung surfactant. Chem Pharm Bull (Tokyo) 31:4110-4115

25. Taeusch HW, Keough KMW, Williams M, Slavin R, Steele E, Lee AS, Phelps D, Kariel N, Floros J, Avery ME 1986 Characterization of bovine surfactant for infants with respiratory distress syndrome. Pediatrics 77:572-581

26. Seidner S, Pettenazzo A, Ikegami M, Jobe A 1988 Corticosteroid potentiation of surfactant dose response in preterm rabbits. J Appl Physiol 64:2366-2371

27. Bligh EG, Dyer WJ 1959 A rapid method of total lipid extraction and purification. Can J Biochem Physiol 37:911-917

28. Bartlett GR 1959 Phosphorous assay in column chromatography. J Biol Chem 234:466-468

29. Jobe A, Ikegami M, Jacobs H 1981 Changes in the amount of lung and airway phosphatidylcholine in 0.5-12.5-day-old rabbits. Biochim Biophys Acta 664:182-187

30. Jacobs H, Jobe A, Ikegami M, Conaway D 1983 The significance of reutilization of surfactant phosphatidylcholine. J Biol Chem 258:4159-4165

31. Oulton M, Fraser M, Dolphin M, Yoon R, Faulkner G 1986 Quantification of surfactant pool sizes in rabbit lung during perinatal development. J Lipid Res 27:602-612

32. Wright JR, Wager RE, Hawgood S, Dobbs L, Clements JA 1987 Surfactant apoprotein $\mathrm{M}_{\mathrm{r}}=26,000-36,000$ enhances uptake of liposomes by type II cells. J Biol Chem 262:2888-2894

33. Ikegami M, Jobe AH, Yamada T, Seidner SR, Priestley A, Ruffini L 1988 Surfactant metabolism in surfactant treated premature ventilated lambs. Pediatr Res 23 (suppl):530(abstr)

34. Possmayer F, Tokmakjian S, Harding P 1985 Pool sizes of the precursors for phosphatidylcholine synthesis in developing lung. In: Zappia V, Kennedy EP, Nilsson BI, Galletti P (eds) Novel Biochemical, Pharmacological and Clinical Aspects of Cytidinediphosphocholine. Elsevier Science Publishers, Amsterdam, pp 91-104

35. Ikegami M, Jobe AH, Seidner SR, Yamada T 1989 Gestational effects of corticosteroids and surfactant in ventilated rabbits. Pediatr Res $25: 32-37$ 